\title{
The Behavior and Representation of Geminate Consonants in Moroccan Arabic
}

\author{
Ayoub Noamane * \\ (Mohammed V University, Morocco)
}

\begin{abstract}
The present paper explores the special behavior of geminate consonants in Moroccan Arabic vis-á-vis short consonants and consonant clusters. By way of comparison, it is shown that geminates exhibit properties that are reminiscent of both unit structures and cluster structures. In particular, we reveal that geminates in MA demonstrate an inconsistent behavior in relation to the process of schwa epenthesis. In this context, we ask whether geminates get split up in MA, and when and how that happens. In order to characterize the patterning of geminates in MA, different phonological representations of geminates are examined against the variable behavior of geminates. On this basis, it is eventually suggested that geminates should be depicted as two root nodes that are underlyingly associated with a mora at the prosodic level.
\end{abstract}

Keywords: geminate behavior, geminate representation, Moraic Theory, autosegmental phonology, prosodic morphology, Moroccan Arabic

\section{Introduction}

A significant cross-linguistic characteristic concerning the phonological behavior of geminates is that they sometimes combine properties of sequence structures as well as singleton structures. In other words, within the same language, geminates may simultaneously pattern with consonant clusters with respect to certain rules and with short consonants with regard to other rules. This dual function of geminates has made it hard for phonologists to provide a consistent phonological representation that can account for this observed, and apparently erratic, behavior (Leben, 1980; Saib, 1977). Furthermore, the treatment of geminate consonants becomes even more challenging when phonologists try to put forward a cross-linguistic account of geminate tendencies. Every attempt in this direction is marred by major cross-linguistic irregularities and variations (Muller, 2001; Curtis, 2003; Kubozono, 2017).

\footnotetext{
* Dr. Ayoub Noamane: Assistant Professor, Department of English Studies, Faculty of Letters and Human Sciences, Mohammed V University in Rabat, Morocco. E-mail: noamane.ayoub@gmail.com.
} 
Moroccan Arabic is one of the few other languages that make a distinction between short and long consonants (e.g. Russian (Dmitrieva, 2017), Tashlhit (Bensoukas, 2001), Japanese (Kubozono et al., 2008), Trukese (Hart, 1991), Somali (Blevins, 2005)). Geminate consona -nts permeate the MA language system. Not only do they phonemically contrast with short consonants (e.g. mra 'woman' vs. marra 'one time'), but they also happen to be phonologically and morphologically derived (e.g. $l$-suq vs. sssuq 'the market'; $k t a b$ vs. $k \partial t t a b$ 'write') (Noamane, 2018b, 2020a). MA is an exemplary language where geminates display characteristics of both consonant sequences and singletons. Evidence for this comes from the distribution of geminates and their behavior in response to a number of phonological and morphological processes. For the sake of typological validity, our discussion of the patterning of geminates in MA will be substantiated by data from various other languages.

This chameleonic geminate behavior raises the following pressing question: Should geminates be interpreted as sequences of short consonants, as single long consonants or as segments that are similar to and, at the same time, different from both? In answering this question, different models of phonological representation will be evaluated for their ability to adequately capture and explain the behavior of geminates in MA and elsewhere.

The organization of this paper is laid out as follows. Sect. 2 demonstrates the dual behavior of geminate consonants in MA. More specifically, Sect. 2.1 highlights the patterning of geminates with consonant clusters whereas Sect. 2.2 showcases the monolithic properties of geminates with regard to some specific rules. Sect. 3 addresses the phonological representation of geminates. Precisely, Sect. 3.1 concerns itself with geminate representation in linear phonology while Sect. 3.2 addresses the non-linear approaches to geminate representation and culminates in proposing a new model of representation. The square brackets [ ] on all phonetic transcriptions in this paper are omitted.

\section{The dual behavior of geminates in MA}

This section addresses the duality that characterizes the behavior of geminates in MA. It shows how geminate consonants behave as sequence structures on some occasions (Sect. 2.1) and as unit structures on other occasions (Sect. 2.2).

\subsection{Geminates as sequence structures}

To begin with, geminate consonants in MA have distributional properties that are identical to those of consonant clusters. As the language allows consonant clusters in all positions, they can be word-medial, word-initial as well as word-final.

(1) The distribution of clusters in MA

$$
\begin{aligned}
& \text { Word-initially Word-medially Word-finally }
\end{aligned}
$$

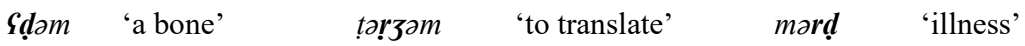


The Behavior and Representation of Geminate Consonants in Moroccan Arabic

\begin{tabular}{|c|c|c|c|c|}
\hline $\int y a b$ & 'to drink' & fərзżm & 'a window' & kalb \\
\hline zbəd & 'to pull' & $k a r k a b$ & 'to roll' & forx \\
\hline
\end{tabular}

Word medial clusters extend across two syllables. The first member of the cluster is typically syllabified as the coda of the previous syllable and the second member is syllabified as the onset of the ensuing syllable. At the margins, however, complex onsets and codas are not tolerated in MA. Thus, when clusters appear at the margins, the spare consonant is syllabified as the head of its own syllable. Interestingly, geminates are distributed similarly.

(2) The distribution of geminates in MA

\begin{tabular}{|c|c|c|c|c|c|}
\hline \multicolumn{2}{|c|}{ Word-initially } & \multicolumn{2}{|c|}{ Word-medially } & \multicolumn{2}{|c|}{ Word-finally } \\
\hline$d d i$ & 'to take' & sənna & 'tooth' & sadd & 'to close' \\
\hline ssuq & 'the market' & gaffa & 'bag' & 3orr & 'to pull' \\
\hline Ilimun & 'the orange' & $s a s \mathcal{~} a$ & 'clock' & Gaḍ & 'to bite' \\
\hline
\end{tabular}

For this reason, geminates tend to be syllabified in much the same way as clusters, hence arguably regarded as clusters of two identical singletons. This is subject to a great deal of controversy as will be discussed in due time. The distribution properties of geminates and clusters in MA can be summed up as follows:

(3) The distribution and syllabification of geminates and consonant clusters in MA

$\begin{array}{lll} & \text { CC clusters } & \text { Geminates } \\ \text { Word-medially } & \text { VCx.CyV } & \text { VCx.CxV } \\ \text { Word-initially } & \text { Cx.CyV } & \text { Cx.CxV } \\ \text { Word-finally } & \text { CVCx.Cy } & \text { CVCx.Cx }\end{array}$

In addition, the language has a common regular rule of schwa epenthesis which takes place for the purpose of breaking up impermissible consonant clusters. In consonant-only words, the domain of such a rule is restricted to a minimum sequence of three unparsed consonants (e.g., CCC). That is, whenever a sequence of more than two unsyllabified consonants occurs, an epenthetic schwa breaks it. Consider the following examples:

(4) Schwa epenthesis in MA

\begin{tabular}{|c|c|c|}
\hline Root & Verb & Gloss \\
\hline a. $/ \int r b /$ & frab & 'to drink' \\
\hline /qtl/ & qtal & 'to kill' \\
\hline$/ k t f /$ & $k t a f$ & 'shoulder' \\
\hline b. /trgm/ & torzam & 'to translate' \\
\hline /frrzm/ & forzam & 'window' \\
\hline /fṛml/ & formal & 'to marinate' \\
\hline
\end{tabular}

These examples show that a cluster of three consonants triggers the epenthesis of only one schwa, while a sequence of four consonants triggers the epenthesis of two schwas. On 
this basis, it is believed that if geminates were single consonants, sequences like those in (5a) would not be expected to trigger schwa epenthesis at all and those in (5b) are expected to trigger the epenthesis of only one schwa.

(5) Geminates in a sequence

\begin{tabular}{|c|c|c|c|}
\hline . $/ s d d /$ & 'close' & b. /kttb/ & 'write' \\
\hline$/ \hbar \boldsymbol{l l} /$ & 'open' & /hrryb/ & 'escape' \\
\hline$/ \int d d /$ & 'catch' & $\mid t l l f /$ & 'lose' \\
\hline$/ d \boldsymbol{q} \boldsymbol{q} /$ & 'knock' & /frrgb/ & 'drink' \\
\hline$/ \int \boldsymbol{q} \boldsymbol{q} /$ & 'crack' & $/ k m m / /$ & 'wrinkle' \\
\hline
\end{tabular}

That is, if the roots in (5a) were bi-consonantal, the domain of schwa epenthesis would be unsatisfied. Yet, schwa epenthesis does take place as far as these sequences are concerned. This entails that their geminates count as two consonants, which, together with the first consonant, make a three-consonant cluster. Also, if the structures in (5b) were tri-consonantal, counting their geminates as single long consonants, we would expect only one epenthetic schwa in their output forms. However, these structures trigger the epenthesis of two schwas in the same way the quadri-segmental roots in (4) do.

(6) Geminates and schwa triggering

\begin{tabular}{|c|c|c|c|}
\hline a. $\quad$ sodd & 'to close' & b. kattab & 'to make write' \\
\hline$\hbar$ ћll & 'to open' & horṛob & 'to make escape' \\
\hline $\int \boldsymbol{\partial} d d$ & 'to catch' & tollof & 'to make disappear' \\
\hline$d \boldsymbol{\partial q q}$ & 'to knock' & forrqab & 'to make drink' \\
\hline $\int \partial q q$ & 'to crack' & kəmməs & 'to wrinkle' \\
\hline
\end{tabular}

One could claim that schwa epenthesis breaks any number of consonant clusters, including bi-consonantal ones. This could explain the position of the schwa in (6a), where it occurs between the geminate and the first radical consonant. But such a claim would mean that a schwa should break any sequence of two consonants, including those in (4), reiterated in (7) with the expected structure under this view.

(7) A schwa between each two consonants

\begin{tabular}{|c|c|}
\hline a. $/ / r b b /$ & ${ }^{*}$ for $\boldsymbol{p} \boldsymbol{b} b$ \\
\hline lqtl/ & ${ }^{*} q \partial t \partial l$ \\
\hline$/ k t f /$ & ${ }^{*} k \boldsymbol{\partial} t \boldsymbol{\partial} f$ \\
\hline b. /trgm/ & ${ }^{*}$ torazam \\
\hline /frrzm/ & *arazam \\
\hline /fṛml/ & ${ }^{*}$ or \\
\hline
\end{tabular}

Nevertheless, these structures are ungrammatical, which emphasizes the fact that the domain of schwa epenthesis is rather a sequence of three consonants or more. If (6a) is viewed as a case of schwa epenthesis in the context of a bi-consonantal root, then (7) 


\section{The Behavior and Representation of Geminate Consonants in Moroccan Arabic}

should also be possible. By way of explanation, if schwa is capable of creating bimoraic prosodic words of the shape $\mathrm{C}_{1} \partial \mathrm{C}_{2}$, nothing should prevent it from occurring in open syllables as in (7). ${ }^{(1)}$ Therefore, the geminates in (6a) cannot count as one single segment, but as two. As a result, we can maintain the generalization that words like $\mathrm{C}_{1} \partial \mathrm{C}_{2}$ and syllables like $\mathrm{C} ə$ are equally ungrammatical. With that said, geminates appear to behave as a sequence of consonant clusters with respect to the triggering of schwa epenthesis.

There is another case of epenthesis in MA that occurs exclusively in verbs ending in geminates. As the data in (8) illustrates, when these verbs are inflected for the past form, the vowel $/ i$ / is inserted between the geminate and the perfective personal pronoun if the latter starts with a consonant. Were it a single segment, the geminate would be fully contained in the first syllable, functioning as a coda. However, it behaves as a cluster of two independent segments with the second member triggering epenthesis and forming a syllable of its own.

\begin{tabular}{|c|c|c|c|}
\hline (8) a. /sdd+t/ & $s_{1} \partial d_{2} \cdot d_{3} \boldsymbol{i} t$ & 'I closed' & ${ }^{*} s_{l} \partial d d_{2} \cdot t$ \\
\hline$/ s d d+n a /$ & $s_{1} \partial d_{2} \cdot d_{3} \boldsymbol{i} \cdot n a$ & 'we closed' & ${ }^{*} s_{l} \partial d d_{2} \cdot n a$ \\
\hline$/ s d d+t i /$ & $s_{1} \partial d_{2} \cdot d_{3} \mathbf{i} \cdot t i$ & 'you closed' & ${ }^{*} s_{l} \partial d d_{2} \cdot t i$ \\
\hline $\mid s d d+t u /$ & $s_{1} \partial d_{2} \cdot d_{3} \boldsymbol{i} \cdot t u$ & 'you (pl.) closed' & ${ }^{*} s_{l} \partial d d_{2} \cdot t u$ \\
\hline b. $/ s d d /$ & sad.d & 'he closed' & \\
\hline$/ s d d+a t /$ & sad.dat & 'she closed' & \\
\hline$/ s d d+u /$ & sad.du & 'they closed' & \\
\hline
\end{tabular}

Note that epenthesis does not take place if the relevant personal pronoun starts with a vowel or if the verb stem does not take any pronoun, as illustrated by (8b).

Another piece of evidence showing the patterning of geminates with consonant clusters comes from the derivation of the instrument noun from roots ending in a geminate. At this level of the discussion, it is assumed that the instrument noun is derived by doubling the second radical segment of the base form and affixing a vowel $/ a /$ before and after the last consonant (see Noamane (2018c) for a comprehensive account of instrument nouns and morphological gemination in MA).

(9) Root

$\begin{array}{clll}\text { a. } / y s l / & \text { 'to wash' } & \text { yassala } & \text { 'washer' } \\ / k w a / & \text { 'to weld' } & \text { kawwaja } & \text { 'welding machine' } \\ / t l y / & \text { 'ice' } & \text { tallaza } & \text { 'fridge' } \\ \text { b. } / s_{1} d_{2} d_{3} / & \text { 'to close' } & \text { saddada } & \text { 'cover' } \\ / \hbar_{1} k_{2} k_{3} / & \text { 'to scratch' } & \hbar \text { tokkaka } & \text { 'mincer' }\end{array}$

\footnotetext{
(1) $\mathrm{C}_{1} \partial \mathrm{C}_{2}$ word forms in MA do not belong to major lexical categories (e.g. mən 'from'). This is to say that word minimality condition applies primarily to content words.
} 


$$
\mid r_{1} \int_{2} \int_{3} / \quad \quad \text { 'to spray' } \iint a f a \quad \text { 'sprayer' }
$$

The point here is that the roots in (9b) are treated in the same way as the roots in (9a), in that the second segment in each category is doubled regardless of whether it is a member of a consonant cluster or 'part' of a geminate consonant. What one would expect if the geminates in $(9 \mathrm{~b})$ were single long consonants is that the whole segment would be doubled and not just some part of it. If that were the case, we would have the following structures instead:

$$
\begin{aligned}
& \text { (10) } / s_{1} d d_{2} / \quad \text { 'to close' } \quad{ }^{*} \text { saddadda }
\end{aligned}
$$

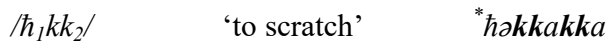

$$
\begin{aligned}
& / r_{1} \iint_{2} / \quad \text { 'to spray' }{ }^{*} \text { ra } \iint a \iint a
\end{aligned}
$$

To extend the range of situations where geminates act as a sequence of consonants in MA, we refer to cases where they get split by vowels in the exact same way as other consonant clusters do. This happens in the case of deriving the past participle from roots ending with geminates. For concrete examples, see the data below:

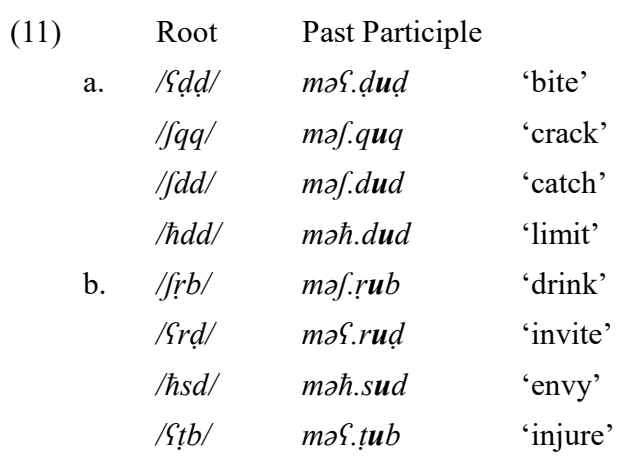

In (11), we notice that the derivation of the past participle form involves the prefixation of $/ \mathrm{m}$-/ to the root and the infixation of $/-u-/$ between the last two radical segments (check Noamane (2020b) for a detailed analysis of past participles in MA). The infixed vowel splits consonant clusters forming syllables of the shape CVC. Both root categories in (11) behave similarly with regard to this infixed vowel, that is as sequences of independent consonants whose two last members are breakable by vocalic material.

The patterning of geminates as sequences of consonants recurs across a variety of other languages. One such a language is Tamazight, for which Saib (1977) suggests a sequential analysis of its geminates. Tamazight has two rules of schwa epenthesis. One rule inserts a schwa before two consonants followed by a vowel. Another rule places a schwa between the last two consonants of tri-segmental sequences. These are reproduced below for easy reference:

(12) Schwa epenthesis in Tamazight

a.<smiles>[4H][14C](Cl)([14Cl])[14CH]O</smiles> 


\section{The Behavior and Representation of Geminate Consonants in Moroccan Arabic}

b. $\varnothing \longrightarrow$ o $/ \mathrm{CC}-\mathrm{C} \#$

These two rules treat geminates and consonant clusters equally, in that they apply in the presence of each. The first rule applies unrestrictedly before a geminate followed by a vowel and the second one consistently interprets a sequence of a geminate plus a singleton as a tri-consonantal cluster. The data below (Saib, 1977) demonstrates how this works:

\begin{tabular}{|c|c|c|}
\hline (13) a. $/ x d m /$ & $\boldsymbol{a x d} \boldsymbol{\partial m}$ & 'work' \\
\hline /rzm/ & orzam & 'open' \\
\hline b. $/ k k s /$ & okkas & 'take off' \\
\hline /qqn/ & əqqan & 'close' \\
\hline c. $/ f a /$ & $f a$ & 'yawn' \\
\hline$/ s u /$ & su & 'drink' \\
\hline
\end{tabular}

First, the rule in (12b) applies consistently to the roots in (13a) and (13b) by inserting a schwa before the last consonant. This creates an environment that triggers the application of the rule in (12a), which places a schwa before a sequence of two consonants followed by a vowel. These rules could not apply if geminates were single consonants since rule (12b) does not apply to a sequence of two consonants, while rule (12a) never applies before one consonant followed by a vowel as can be proved by considering the items in $(13 \mathrm{c}) .{ }^{(1)}$

Similar properties are found in Leti, treated in Hume et al. (1997), where geminates and consonant clusters alike pattern together in connection with a number of rules, in opposition to singletons. Leti has a word final VC metathesis rule which applies before two-consonant clusters and geminates while it is blocked before single consonants. Also, in Leti, a word final $/ a /$ is deleted only when it precedes a short consonant, but not when a consonant cluster or a geminate follows. These two rules are illustrated in (14a) and (14b), respectively.

(14) a. Word final VC metathesis in Leti

$\begin{array}{lll}\text { /kunis+vnutan/ } & \text { kunsivnutan } & \text { 'iron key' } \\ \text { /vuar+spou/ } & \text { vu:raspou } & \text { 'schooner mountain' } \\ \text { /ukar+ppalu/ } & \text { ukrappalu } & \text { 'index finger' } \\ \text { /maun+ppuna/ } & \text { ma:nuppuna } & \text { 'bird's nest' }\end{array}$

b. Word final /a/ deletion in Leti

$\begin{array}{lll}\text { /samela+nura/ } & \text { samelnura } & \text { 'tricoloured squirrel' } \\ \text { /samela+ttcnan/ } & \text { samelattcnan } & \text { 'mouse's spine' }\end{array}$

\footnotetext{
(1) Other aspects of Tamazight phonology support a featural analysis of geminates. For instance, in the derivation of the intensive form of verbs, underlying geminates fail to further geminate, contradicting the sequential quality they display elsewhere. To solve this problem, Saib (1977) promotes the sequential analysis by suggesting a phonetically based universal convention whereby the two elements of a geminate are redundantly specified as [+long] to fortify each other. This way the structure description of each member of the geminate cluster would be different from that of normal consonants.
} 
In addition to this, the distribution of geminates and consonant clusters in Leti supports their patterning since they are unified by the fact of being limited to word-initial position, for example ppikan 'plate' vs. ptuna 'star'.

Further distributional evidence for the patterning of geminates and consonant clusters is provided by Leben (1980), based on data from Hausa. Leben points out the fact that the restrictions that govern the distribution of $\mathrm{CC}$ clusters are identical to the restrictions that regulate the distribution of geminates. These restrictions are borrowed here from Leben (1980):

(15) The distribution of geminates and CC clusters in Hausa

$$
\begin{array}{ll}
\text { Geminates } & \text { CC clusters } \\
{ }^{*} \mathrm{GV} \ldots & { }^{*} \mathrm{CCV} \ldots \\
{ }^{*} \ldots \mathrm{VG} & \ldots{ }^{*} \mathrm{VCC} \\
{ }^{*} \ldots \mathrm{GC} \ldots \text { and }^{*} \ldots \mathrm{CG} \ldots & \ldots{ }^{*} \mathrm{CCC} \ldots \\
\ldots \text {. . . . ... } & \ldots \text {. VCCV ... (possible position) }
\end{array}
$$

The idea here is that the distributional parallel between geminates and clusters in Leti and Hausa reveals that they are structurally equivalent. Otherwise, the only other possible explanation is that their identical distribution is accidental. This issue will be a matter of further discussion. In the following section, we introduce the properties that geminate consonants in MA share with unit structures.

\subsection{Geminates as unit structures}

Considering all the above-mentioned commonalities between geminates and consonant clusters, it seems very convincing that they should be treated the same. That is, geminates ought to be interpreted as clusters of two identical consonants. Nonetheless, the picture is not quite complete yet since the two structures were reported to diverge from each other in many ways. More specifically, geminates were shown to resist and block rules of epenthesis, metathesis, syncope and spirantization that normal consonant clusters undergo or trigger (Kenstowicz \& Pyle, 1973; Guerssel, 1977, 1978; Schein \& Steriade, 1986; Hayes, 1986). This property of geminates is commonly referred to in the literature as geminate integrity and inalterability.

Geminate integrity and geminate inalterability were first made known by the seminal works of Kenstowicz \& Pyle (1973) and Guerssel (1977). Yet, these treatments do not claim that geminates should be regarded as unit segments as a result. In fact, they advance a sequential analysis that regards geminates as a cluster of two alike consonants. In defense of this claim, they argue that geminates are just a special type of consonant clusters that behave differently.

Kenstowicz \& Pyle (1973) starts by emphasizing the sequential make-up of geminates drawing on data from Sierra Miwok. The language is reported to have a shortening rule that 


\section{The Behavior and Representation of Geminate Consonants in Moroccan Arabic}

shortens long vowels before a geminate or a consonant cluster, stated in (16). Also, there is a stress rule which places stress on the first stem vowel if it is long or if it precedes a geminate or a consonant cluster.

(16) $\mathrm{V}: \longrightarrow[-$ long $] /-\mathrm{CC}$

Sierra Miwok has another rule whose effect geminates the word-final singleton of the past form:

(17) $\mathrm{C}_{\mathrm{i}} \longrightarrow \mathrm{C}_{\mathrm{i}} \mathrm{C}_{\mathrm{i}} /$ - ]past

The third rule is a metathesis rule that swaps the order of any final vowel and the consonant that precedes it in the past form:

(18) $\mathrm{C}_{1} \mathrm{C}_{2}$ V]past $\longrightarrow \mathrm{C}_{1} \mathrm{VC}_{2}$

The data to which these rules apply is partially reproduced below where stress is placed above the relevant vowels:

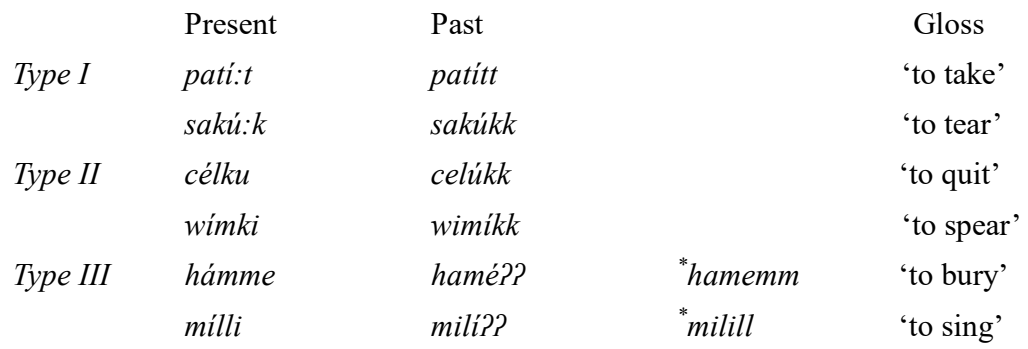

The gemination rule applies first to type I stems turning their final consonants into geminates in the past form. This creates an environment for the shortening rule, hence the relevant long vowels get short. The metathesis rule, on the other hand, applies to type II stems which creates an environment for the gemination rule. However, metathesis does not apply to type III stems although they contain what is believed to be a consonant cluster based on their behavior with regard to the shortening and the stress rules. Yet, geminates appear to diverge from normal consonant clusters by blocking metathesis. Instead, type III stems undergo a degemination rule of their middle geminates followed by a glottal stop insertion stem-finally, which then gets geminated by rule (17).

Kenstowicz \& Pyle proceed to show that this is not a problem for Sierra Miwok alone by citing a whole range of other languages, including Kolami, Kasem and Tunisian Arabic, where geminates diverge from clusters of unalike consonants. On this basis, the authors propose the Integrity Hypothesis as a universal condition on rules:

(20) The Integrity Hypothesis (Kenstowicz \& Pyle, 1973)

All other things being equal, a rule which splits up a geminate cluster is less highly valued than a rule which must be constrained from doing so.

As it stands, this condition prevents rules from applying to geminates even though the latter meets the structural description of those rules. Thus, there is no need for any ad hoc 
restrictions on the application of individual rules.

In much the same spirit, Guerssel (1977) supports the sequential analysis of geminates relying on data from Amazigh, but still points out the fact that geminates do behave differently from clusters of unalike consonants. One piece of evidence that Guerssel provides in favor of the geminate-cluster patterning has to do with a rule of syncope in Amazigh which deletes a schwa before CV (e.g., /zar-i/ - zri 'throw me down'). Yet, the syncope rule gets blocked when followed by a consonant cluster or a geminate (e.g., /baddal/ - "bdda 'to change').

Nevertheless, according to Guerssel (1977), geminates are not consistent in their patterning with consonant clusters. This is evidenced by a process of metathesis that affects normal clusters exclusively (e.g., $/ u z l+\partial x /-u z \partial l x$ 'I hang'). As for geminates, the process is blocked (e.g., /sarrag/ - 'sararg). To account for this observed behavior, Guerssel (1977) suggests a constraint on the application of phonological rules dubbed the Adjacency-identity Constraint. This constraint stipulates the following:

(21) The Adjacency-Identity Constraint (Guerssel, 1977)

Given two segments $A 1 A 2$ where $A 1=A 2$, a phonological rule can alter the adjacency of $A 1 A 2$ if and only if it alters the identity of $A 1$ or A2.

The proposed constraint prevents rules of metathesis and epenthesis from splitting geminates unless the featural identity of one is altered. Again, this is devised to avoid any ad hoc restrictions on rules while justifying the special status of geminate clusters.

In this light, geminates in MA appear to obey the stipulation of both the Integrity Hypothesis and the Adjacency-Identity Constraint. More specifically, geminates in MA behave as unbroken segments, in that they resist schwa epenthesis that other normal consonant clusters undergo. In the normal case, a schwa occurs between the last two consonants of every tri-consonantal verb or adjective (e.g., $\mathrm{CC} 2 \mathrm{C}$ ), unless they end in a geminate, consider (22a) and (22b), for example. In the presence of a geminate, the schwa appears between the first consonant and the geminate of these verbs or adjectives (e.g., $\left.\mathrm{C}_{2} \mathrm{C}_{\mathrm{i}} \mathrm{C}_{\mathrm{i}}\right)$. Also, when a noun ends in a full vowel, see (22c), a schwa is inserted between the two initial consonants, except when it is a geminate.

(22) Geminate integrity and schwa epenthesis

a. Verbs

$\begin{array}{cll}\text { (i) } \text { s } \boldsymbol{\partial} d d & \text { 'close' } & { }^{*} d \boldsymbol{\partial} d \\ \hbar \boldsymbol{\partial} l l & \text { 'open' } & { }^{*} \hbar l \boldsymbol{\partial} l \\ \int \boldsymbol{\partial} d d & \text { 'catch' } & { }^{*} \int d \boldsymbol{\partial} d \\ d \boldsymbol{\partial} q q & \text { 'knock' } & { }^{*} d q \boldsymbol{\partial} q \\ \text { (ii) } h r \boldsymbol{\partial} b & \text { 'escape' } & \\ t \text { təof } & \text { 'disappear' } & \end{array}$


The Behavior and Representation of Geminate Consonants in Moroccan Arabic

\begin{tabular}{|c|c|c|}
\hline frab & 'drink' & \\
\hline$k b \boldsymbol{\partial} r$ & 'grow' & \\
\hline \multicolumn{3}{|c|}{ b. Comparatives } \\
\hline (i) $r \boldsymbol{\partial} q q$ & 'thin' & ${ }^{*} r q \boldsymbol{\partial} q$ \\
\hline$x \boldsymbol{\partial f f}$ & 'light' & ${ }^{*} x f \partial f$ \\
\hline bann & 'tasty' & ${ }^{*} b n \boldsymbol{\prime}$ \\
\hline$s \underline{a} \hbar \hbar$ & 'strong' & ${ }^{*} s ̧ \hbar \hbar$ \\
\hline (ii) tqal & 'heavy' & \\
\hline twal & 'tall' & \\
\hline ylad & 'fat' & \\
\hline shal & ‘easy’ & \\
\hline \multicolumn{3}{|l|}{ c. Nouns } \\
\hline (i) ssma & 'the sky' & ${ }^{*}$ sosma \\
\hline ddra & 'the corn' & * dodra \\
\hline$s s \underline{d ̣} d a$ & 'the rust' & *șașda \\
\hline (ii) katra & 'plenty' & \\
\hline$\hbar \boldsymbol{\jmath} / m a$ & 'shyness' & \\
\hline lakra & 'the rent' & \\
\hline
\end{tabular}

On this ground, we could claim that the rule responsible for schwa epenthesis in MA is subject to the Integrity Hypothesis and the Adjacency-Identity Constraint. This blocks the rule from applying to geminates while it still applies to other consonant clusters. However, the fact that geminates cross-linguistically diverge from consonant clusters could indicate a difference in their structure. This view will be considered for further discussion later in this work (For more on geminate integrity in MA, see Noamane, 2018a).

To recapitulate, the behavior of geminate consonants has been shown to be marked by indeterminacy, in the sense that geminates exhibit properties of both singletons and consonant clusters. On the one hand, they act as sequences of two-like consonants that have the exact same distributional restrictions and the structural effects as sequences of unlike consonants. On the other hand, rules of epenthesis and metathesis, which typically split normal consonant clusters, are blocked from affecting them, in much the same way they cannot affect singletons. In what follows, we will be discussing the various phonological representations that were proposed to explain the special behavior of geminates.

\section{The phonological representation of geminates}

This section evaluates the various representations that have been attributed to geminate consonants in phonological theory and ultimately proposes a new model of representation that reconciles the prosodic and segmental properties of geminates in MA. 


\subsection{The linear approach to geminate representation}

In the framework of linear phonology (Chomsky and Halle, 1968), phonological length was accounted for in terms of the binary feature [-/+long]. Under this view, geminates could be perceived either as single unit segments that are [+long] (i.e., featural analysis) or as a sequence of two-like consonants, $\mathrm{C}_{\mathrm{y}} \mathrm{C}_{\mathrm{y}}$ (i.e., sequential analysis).

(23) Geminate representations in linear phonology

$\begin{array}{ccc}\mathrm{C} & \mathrm{C}_{\mathrm{y}} & \mathrm{C}_{\mathrm{y}} \\ {[+ \text { long }]} & {[- \text { long }]} & {[\text {-long }]}\end{array}$

The featural analysis of geminates can adequately explain the integrity that geminates display with regard to rules of epenthesis and metathesis. That is, if geminates are monolithic segments that are long, no phonological material can penetrate their featural make-up. However, the featural analysis fails to justify the structural parallel between geminates and other consonant clusters. If we choose to hold to a featural analysis, the distributional parallel between geminates and consonant clusters should be rendered accidental. Besides, the rules triggered by consonant clusters would need to be modified for their environment. Instead of only applying in the context of consonant clusters, they should apply in the presence of long consonants as well. This means that long consonants and consonant clusters will be made equivalent. According to Saib (1977), this "makes a simple rule complex by stating two environments instead of one".

The sequential analysis does a good job as far as capturing the observed parallel between geminates and normal clusters is concerned. Yet, it falls short of explanatory adequacy when it comes to explaining the ability of geminates to block rules that are otherwise applicable to other clusters. The works of Kenstowicz \& Pyle (1973) and Guerssel (1977) fall under the purview of linear phonology. As mentioned before, they both argue for a sequential analysis of geminates. Such an analysis can account for geminate blockage only by resorting to additional stipulations on phonological rules. Here comes the role of the Integrity Hypothesis and the Adjacency-Identity Constraint. There are two problems related to such stipulations. First, they are stated in the form of universal inviolable constraints. This is seen as a problem because there are many exceptions that contradict these constraints. For example, MA is laden with productive processes that split geminates, the past participle as a case in point. Second, they indicate that the representational mechanism of the theory is insufficient.

As far as the MA data presented so far is concerned, neither of the above-mentioned linear analyses seem to adequately account for the observed patterns. The behavior of geminates in MA is quite complex. The fact that geminates in MA split on some occasions but hold their integrity in others is troublesome for both the featural analysis and the sequential one. If a geminate is a segment specified for the feature [+long], then the rule of 


\section{The Behavior and Representation of Geminate Consonants in Moroccan Arabic}

schwa epenthesis interprets it as an indivisible unit. That is why the geminates in (23) above are not split by schwa. In this case, we would be asking: why do geminates still count as two segments in triggering schwa epenthesis? Another question would be: why do the same geminates split elsewhere?

\begin{tabular}{|c|c|c|c|}
\hline Root & Verb & Past Participle & Gloss \\
\hline$/ \varsigma d \underline{d} / /$ & Gadd & $m \partial G \underline{\boldsymbol{d}} u \boldsymbol{d}$ & 'bite' \\
\hline$/ \int q q /$ & $\int \partial q q$ & $m \partial \int \boldsymbol{q} u \boldsymbol{q}$ & 'crack' \\
\hline$/ \int d d /$ & $\int \partial d d$ & $m \partial \int d u d$ & 'catch' \\
\hline$/ \hbar d d /$ & $\hbar$ ћadd & $m \partial \hbar d u d$ & 'limit' \\
\hline
\end{tabular}

This data set is problematic not only for the featural analysis but also for the sequential one. The latter would make use of some constraint (i.e., Integrity Hypothesis or the Adjacency-Identity Constraint) on rules to account for geminate integrity. However, it is obvious that such a constraint would not be obeyed by all the rules of MA where geminates are commonly split (e.g., the past participle). Thus, it is clear that a linear analysis is struggling to explain the dual function of geminates.

\subsection{The non-linear approach to geminate representation}

\subsubsection{The autosegmental approach}

The advent of autosegmental phonology (Leben, 1973; Goldsmith, 1976; McCarthy, 1979) has opened new avenues for phonological representations. One of the major contributions of this framework is the autosegmentalization of tonal and melodic features, separating them from their linearly-ordered segmental positions. These components are then placed on distinct interacting tiers, namely the melodic tier and the timing (or skeletal) tier, allowing for multiple associations between these two levels of representation. In this theory, segmental length is represented as one melodic element multiply-linked to two segmental positions.

(25) Geminate representation in autosegmental phonology
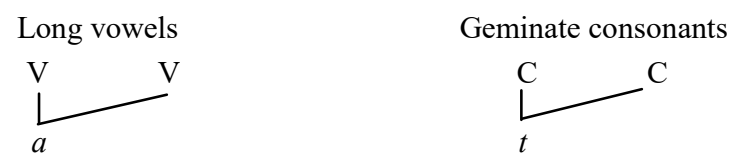

This mechanism allows geminates to be represented differently from both single short consonants and consonant sequences:

(26) Singletons and consonant clusters in autosegmental phonology

$$
\text { a. Short consonants }
$$

C

I b. Consonant clusters<smiles>ICI</smiles> 
The double association structure of long segments is governed by two independently motivated principles of autosegmental phonology: (1) the Obligatory Contour Principle (Leben, 1973; McCarthy, 1986) and (2) autosegmental spreading (Leben, 1973; Goldsmith, 1976). On the one hand, the OCP prohibits the occurrence of adjacent identical melodies morpheme-internally.

(27) Obligatory Contour Principle (OCP) (McCarthy, 1986:208)

At the melodic level, adjacent identical elements are prohibited.

Autosegmental spreading, on the other hand, associates melodic units with their corresponding segmental positions, giving rise to the structure in (25). However, the OCP does not restrict heteromorphemic identical adjacencies, permitting the structure in (26b).

In Arabic, lexical representations are argued to be governed by the OCP. The language is characterized by the absence of patterns of the shape $\mathrm{CxVCxVCy}$, where the two first consonants are identical, whereas patterns of the shape $\mathrm{CyVCxVCx}$ abound. According to McCarthy $(1979,1981,1986)$, this right-left asymmetry is subject to the OCP effect and autosegmental spreading, which is rightward in Arabic. See the following example.
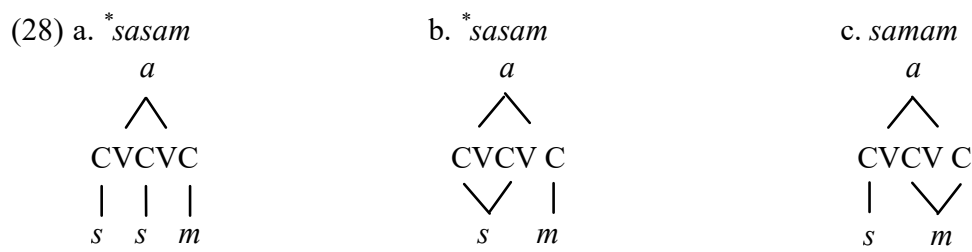

This shows that the structures in (28a) and (28b) are non-occurring due to their violation of the OCP and the rightward spreading rule, respectively. As a result, the only way long tautomorphemic segments can occur in Arabic is via the double linking of melodic segments to the available corresponding timing slots.

Armed with these representational tools, we can now return to our data. We will try to see how an autosegmental approach to geminates may account for the observed geminate patterns in MA. To start with, it will be argued that, like in Classical Arabic, lexical geminates in MA follow from the restriction imposed by the OCP on melodic elements. This means that underlying geminates in MA are the result of rightward spreading of a consonantal root node that is initially associated with a segmental position in the skeleton to another slot in the same skeleton, as the following examples show:

(29) MA underlying geminates in autosegmental phonology

$\begin{array}{ccc}\text { a. Final geminates } & \text { b. Medial geminates } & \text { c. Initial geminates } \\ & a & a \\ \text { I C C } & \text { CC CV } & \text { I CV } \\ \text { s d } & \mid l \cdot & d \\ \text { sadd } & \text { s n } & d d a\end{array}$




\section{The Behavior and Representation of Geminate Consonants in Moroccan Arabic}

Word templates do not distinguish between consonant clusters and geminates. The latter arises when the number of melodic elements provided by the lexicon is less than the available slots in the template. The language then resorts to spreading the rightmost element to cover the remaining slots, resulting in multiple associations. The interesting point here is that even when lexical geminates in MA occur word-initially, they only do so in the case of mono-consonantal lexical items, as in (29c). Hence, being the rightmost melodic element and in the absence of another consonantal melody competing for the relevant slot, the designated melody can spread rightward. This provides us with a structural parallel between geminates in all word positions.

Next, we show how derived geminates in MA are taken care of under the purview of the autosegmental framework. The remarkable aspect of a theory of autosegmentalization is that every geminate structure is the outcome of the spreading mechanism.

The default spreading direction in MA is rightward, but specific rules can make melodic elements spread in the other direction. In the case of total assimilation and compensatory lengthening, spreading goes from right to left.

(30) MA phonologically-derived geminates in autosegmental phonology

a. Total assimilation

$$
\begin{aligned}
& \mathrm{C}+\mathrm{CVC} \quad \mathrm{C}+\mathrm{CVC} \\
& \mathrm{I}|\mathrm{I} \longrightarrow \mathrm{f} \cdot \mathrm{l}| \mathrm{I} \\
& 1+s u q \quad 1+s u q \\
& / 1+\text { suq/ ssuq 'the market' }
\end{aligned}
$$

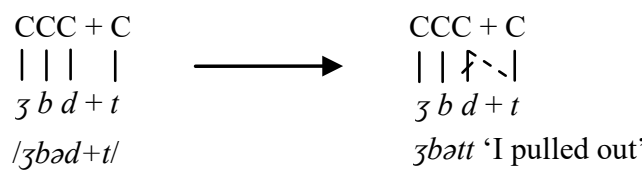

b. Compensatory lengthening

$$
\begin{aligned}
& \mathrm{CVCC}+\mathrm{VC}+\mathrm{V} \quad \mathrm{CVCC}+\mathrm{VC}+\mathrm{V} \quad \mathrm{XXXX}+\mathrm{X} \mathrm{X}+\mathrm{X}
\end{aligned}
$$

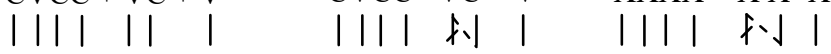

$$
\begin{aligned}
& d a r b+a t+u \quad d a r b+a t+u \quad d a r b+a t+u \\
& \text { dorbatu dorbottu 'she hit him' }
\end{aligned}
$$

In the theory of autosegmental phonology, deletion takes place when a melodic element dissociates from its position on the timing tier. This leaves behind an empty slot. Different languages resort to spreading of nearby melodies to occupy the lingering slot. If what spreads is a vocalic melody, long vowels are created. If what spreads is a consonantal melody, however, a geminate is derived. The case of gemination illustrated in (30b) above is depicted as a case of CL, whereby the delinking of the vowel /a/ of the past tense feminine pronoun /-at/ is believed to trigger the spreading of the consonant $/ t /$ of the same affix. The problem that we face in $(30 \mathrm{~b})$ is that a consonantal melody spreads to a 
V-position. For this reason, we replace the CV tier by the X-slot tier (Levin, 1985). This allows skeletal positions to freely associate with consonantal and vocalic melodies.

Now, we want to show how the theory of autosegmental phonology representationally handles morphologically-derived geminates. To do so, we will briefly review the work of Bennis \& Iazzi (1995), whose analysis of morphological causatives in MA provides some insights into this matter. The basic assumption of this work is that the causative template has the shape of XXXX, where $\mathrm{X}$ is a position on the skeletal tier. The account rests on the idea that different morphological causatives are derived by associating different lexical items to the designated template. For instance, when the melodies of the root $/ f r b /$ are linked to the X-slots of the causative template, we get the causative verb forrab. This analysis is faced with a challenge, however. The spreading direction of MA does not yield the expected form. Only the most rightward melody can spread.

(31) MA morphologically-derived geminates in autosegmental phonology

\begin{tabular}{|c|c|c|c|}
\hline a. Causative template & Lexical entry & Association & Output \\
\hline XXXX & $\left|\int r b\right|$ & $\begin{array}{l}\mathrm{X} X X X \\
|| l^{\prime} \\
\int r b\end{array}$ & ${ }^{*} \int r a b b$ \\
\hline b. Pre-association & & Association & Output \\
\hline $\begin{array}{c}\text { XXXX } \\
\qquad r b\end{array}$ & & $\begin{array}{l}\text { X X X X } \\
\mid \begin{array}{lll}\mid & V & \mid \\
\int & r & b\end{array}\end{array}$ & ${ }^{*} \int r a b b$ \\
\hline
\end{tabular}

To overcome this problem, the authors postulated a rule of pre-association, whereby the second root consonant is pre-linked to the third slot in the template (31b). Subsequently, normal association lines are added. In this way, expected forms are derived.

Now the question is: how does the theory of autosegmental phonology account for geminate integrity and geminate splitting in MA. To answer this question, we refer to the non-crossing association lines constraint of autosegmental phonology. According to this constraint, the application of an epenthesis rule is blocked if it would create an association line that crosses an existing association line:

(32) The non-crossing association line constraint

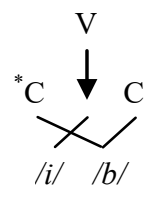

By the same token, we can explain why schwa in MA splits normal consonant clusters while it fails to break up geminates. The following examples illustrate how it works: 
The Behavior and Representation of Geminate Consonants in Moroccan Arabic

(33) Schwa epenthesis in autosegmental phonology
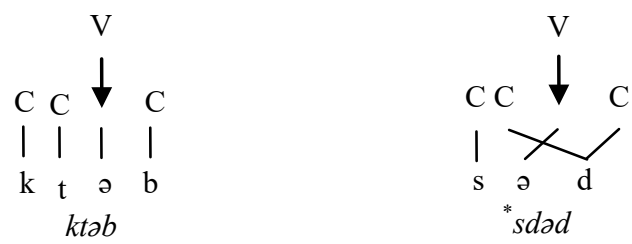

However, some nagging problems still remain. The most striking one is the fact that the melodic elements in autosegmental phonology can exist on different tiers without crossing each other's association lines. This means that we could imagine a schwa on its own independent tier associated with the inserted V-position without interrupting the association lines of the geminate:

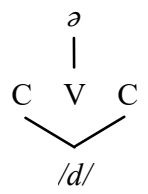

It appears that only morphologically relevant melodies are capable of having their own tiers. Since schwa in MA is purely phonetic, it cannot be placed on an independent tier. This takes us to the case where geminates get split by full vowels in MA, especially in the case of the past participle (e.g. sadd-masdud 'close'). Our stand on this case of geminate splitting relies on the assumption we have just advanced, that morphemes have independent tiers. As a result, the vowel $/ u /$ of the past participle can link to its V-position on the skeletal tier without violating the non-crossing association lines constraint.

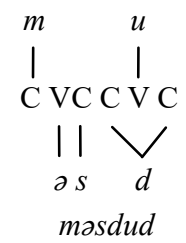

As a consequence, the autosegmental representation of geminates proves quite successful in capturing the dual patterning of geminates. It does so by utilizing independently motivated principles to represent geminates in a consistent way and characterize their behavior without resorting to additional stipulations. Under this theory, all patterns of geminates, be they derived or underlying, emerge from the regulations of OCP, autosegmental spreading and non-crossing association lines constraint. The interaction between these rules produces a single melodic unit doubly associated with two positions on the timing tier. In this way, rules that affect the featural specifications of segments would interpret geminates as single consonants while those that refer to structural information would construe geminates as clusters (Leben, 1980; Schein \& Steriade, 1986; Hayes, 1986). 
The predictions that an autosegmental approach to geminates make about syllable structure are also vital to our discussion. Being represented as two C-slots on the skeletal tier, geminates are expected to be distributed and syllabified in the same way as CC clusters (Curtis, 2003). That is, if a language has CCV and CVCC word shapes, nothing should prevent GV and CVG shapes from existing, and vice versa. Also, if a language counts a syllable with a branching nucleus or a branching rime (i.e., a syllable with one or more X-slots after the nucleus) as heavy, then CVV, CVC, CVCC and CVG should be equally heavy. However, if only branching nuclei are weight-sensitive, then CVC, CVCC and CVG should be all light. The point is that syllables closed with geminates and those closed with singletons should always have the same weight configurations.

Interestingly, these predictions are borne out by the data of MA. As we noted before, geminates share the same distributional properties of CC clusters. Therefore, like consonant clusters, geminates in MA can appear both intervocalically and at the margins (e.g., GV and CVG). A skeletal approach attributes this commonality of distribution to the structural parallel between the two. As far as their syllabification is concerned, geminates and clusters are expected to display the same syllabic behavior. Since branching rimes are weight-sensitive in MA, CVG and CVC syllables would equally count as heavy. In addition, since complex margins are not tolerated in MA, geminates and clusters would never be tautosyllabic. Instead, a syllabic consonant is created out of their constituents to satisfy this requirement.

(36) Initial geminates/cluster

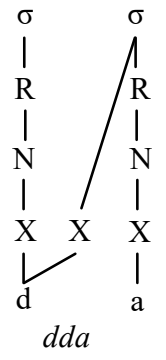

(37) Final geminates/clusters

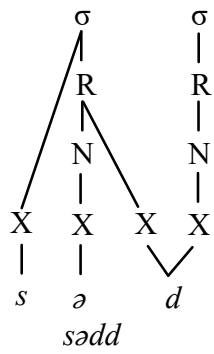

70
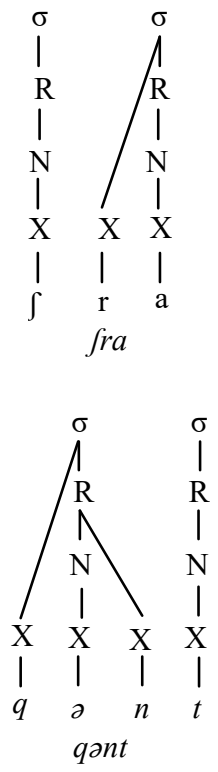


\section{The Behavior and Representation of Geminate Consonants in Moroccan Arabic}

However, autosegmental theory falls short of explanatory power elsewhere. For example, in MA, content words of the shape $\mathrm{C} \partial \mathrm{C}$ and syllables of the shape $\mathrm{C} ə$ are not possible, but CVC words and CV syllables are. In a skeletal approach, $\mathrm{C} ə \mathrm{C}$ and $\mathrm{CVC}$ words are equivalent, and so are $\mathrm{C}$ a and CV syllables. This is because such a theory relies on the counting of skeletal positions. Therefore, both $\mathrm{C} \partial \mathrm{C}$ and $\mathrm{CVC}$ have three positions, while both Cə and CV have two.

(38) The inadequacy of the skeleton:

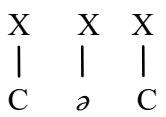

$\begin{array}{ll}\text { X } & \text { X } \\ \text { C } & \text { l }\end{array}$<smiles>[Y]CI(N)[AlH]C</smiles><smiles>[Y][V]C</smiles>

This calls for the consideration of a better prosodic theory. Such a theory should be able to explain the difference between $\mathrm{C} \curvearrowright \mathrm{C} / \mathrm{C} \partial$, on the one hand, and $\mathrm{CVC} / \mathrm{CV}$, on the other. Moraic Theory explains this asymmetry by claiming that schwa is nonmoraic in MA (Bensoukas \& Boudlal, 2012a-b).

\subsubsection{The moraic approach}

Moraic phonology (Hyman, 1985; McCarthy \& Prince, 1986; Hayes, 1989) abstracts away from skeletal prosodic representations by associating melodic elements with moras rather than CV-slots or X-slots. In this theory, the mora is an abstract prosodic unit for measuring syllable weight and representing segmental length. This development in the theory of phonological representation comes as a response to the limitations posed by a theory of skeletal-tiers, which have to do mainly with typological observations about quantity-sensitive phenomena such as stress, word-minimality and Compensatory Lengthening.

In languages with weight-sensitive stress systems, primary stress falls on heavy syllables. In this regard, an open syllable with a long vowel and a closed syllable with a geminate both attract stress in languages that tolerate these structures. Hence, they pattern as heavy by virtue of being bimoraic.

(39)

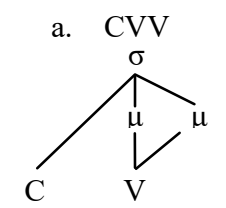

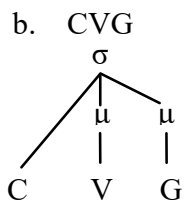

On the other hand, an open syllable with a short vowel or one closed with a singleton count as light since they comprise only one mora. 
(40)

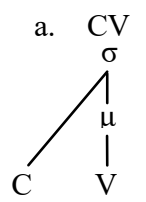

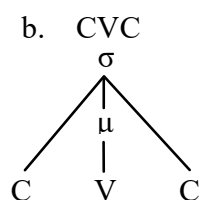

This typology holds true for languages where Weight-by-Position does not apply. In case it does, a CVC syllable would be assigned an additional mora to its coda, making it equivalent to $\mathrm{CV}$ : and CVG syllables.

(41) Weight by Position (Hayes, 1989:258)

$\left.\right|_{\mu} ^{\sigma}$

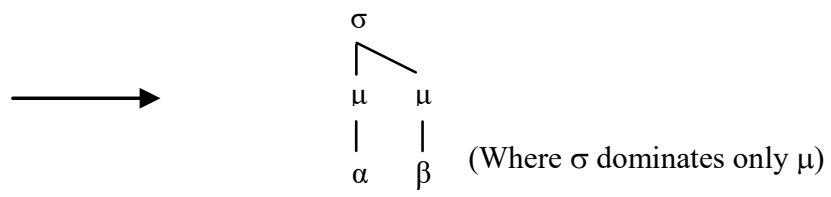

Accordingly, Moraic Theory makes the distinction between CVG and CVC syllables formally possible. In skeletal theory, both syllable shapes are predicted to be quantitatively equivalent under all circumstances. That is, they should both pattern either as heavy in languages with branching rimes or light in languages with no branching rimes. This fact, among many others, justifies the need for the mora and proves the inadequacy of the skeleton. More specifically, it shows that there is some unit (i.e., mora) above the segment that accounts for syllable weight.

On the basis of these observations, long vowels and geminates appear to consistently contribute additional weight to their syllables. For this reason, they are conceived of as being underlyingly moraic. In particular, a geminate is represented as underlyingly associated with one mora. Short consonants, however, are underlyingly nonmoraic. Their moraicity is subject to the language-particular application of Weight-by-Position.

(42) Moraic representation of segmental length

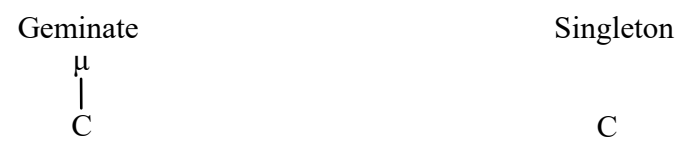

As for vowels, a long vowel is represented as underlyingly linked to two moras while a short one projects only one mora.

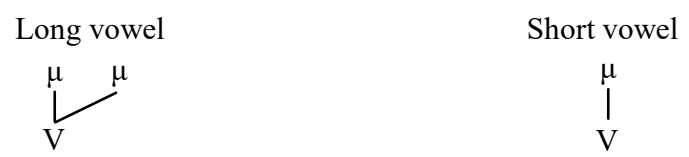

In this sense, Moraic Theory characterizes segmental length and syllable weight by means of the same prosodic principles. In other words, length and weight are both expressed by reference to moras.

The predictions made by Moraic Theory about the underlying representation of 


\section{The Behavior and Representation of Geminate Consonants in Moroccan Arabic}

geminates are corroborated by a plethora of weight-sensitive phenomena. Davis (1994) discusses the case of Hindi where stress is weight-sensitive. In Hindi, CVG syllables, but not CVC ones, pattern with CVV syllables as heavy. Likewise, in the Uto-Aztecan language Cahuilla (Hayes, 1995) and San'ani Arabic (Watson, 2002), CVG and CVV syllables consistently behave as bimoraic with regard to stress assignment.

Further, while singletons in Hindi can follow long vowels (i.e., CVVC), geminates cannot (i.e., ${ }^{*} \mathrm{CVVG}$ ) since the language does not permit trimoraic syllables. Similarly, Davis (2011) mentions the case of Swedish (Kiparsky, 2008) and Koya (Tyler, 1969) which have a vowel shortening process that applies before geminates, but not before singletons. This too is motivated by the avoidance of trimoraic syllables in Swedish and Koya alike.

Another piece of evidence reported by Davis (1999) comes from the prosodic morphology of Hausa and Sinhala where it is believed that, unlike CVC syllables, CVG syllables are treated as bimoraic, on a par with CVV syllables. In Hausa, class 3 plural nouns are derived via the suffixation of one of the following two allomorphs: $-a a C e e$ or -aayee. The first allomorph attaches to monomoraic nominal roots (e.g., dam-aamee 'monitor'). The second allomorph attaches to bimoraic nominal roots (e.g., zoom-aayee 'hare' and tukk-aayee 'bird crest'). Comparably, in Sinhala, there are two allomorphs for the genitive suffix, -ee and -e. The former is selected by monomoraic roots (e.g., mal-ee 'the flower's'), whereas the latter is selected by bimoraic roots (e.g., paar-e 'the street's' and pott-e 'the core's'). This fact illustrates that CVG roots and CVV ones are equivalently bimoraic in Hausa and Sinhala.

In view of this compelling evidence, we proceed to represent the geminates of MA as underlyingly moraic. Under this conception, geminates are expected to inherently contribute prosodic weight to the words they belong to. This representational shift would change our perspective of explaining the observed geminate patterns in many ways. In fact, as appealing as it might seem to adopt a moraic approach to geminates, there are many challenges facing it as far as the geminates of MA are concerned. We decide to endure these challenges and make the moraic approach work for our data. This decision is spurred by our conviction that a unified representation of geminates is more desired in phonological theory.

Under this moraic conception, the identical distributional properties between geminates and consonant clusters would be rendered accidental, instead of being motivated by their structural parallel as predicted by the skeletal approach. In practice, geminates in Moraic Theory are construed as unit (i.e., monolithic) segments. In line with this, the syllabic parallel between geminates and clusters becomes an inadvertent consequence of the fact that both geminates and consonant clusters are hetrosyllabic units, but each for its own special nature. While the members of a consonant cluster would independently belong to 
different syllables, a geminate would be linked to two syllabic nodes.

(44) The syllabification of geminates in Moraic Theory

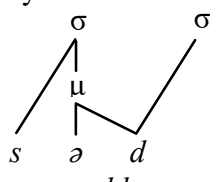

sadd

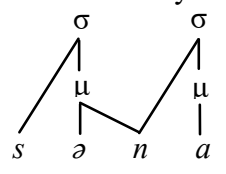

sənna

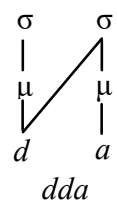

(45) The syllabification of consonant clusters in Moraic Theory
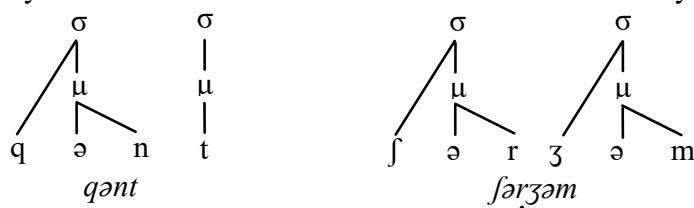

To elaborate, two major differences should be noted between the syllable structure of the items in (44) and those in (45). First, the geminates in (44) are single segments that are simultaneously linked to two syllabic positions while the consonant clusters in (45) are two independent segments, each belonging to a different syllable. Second, the geminates in (44) bring their moras with them, whereas normal consonants are assigned moras depending on their position and function in the syllable (for example, as codas or syllabic consonants).

Additional evidence for the moraic structure can be obtained from the facts of Compensatory Lengthening patterns as delineated by Hayes (1989). According to Hayes, a skeletal approach to Compensatory Lengthening overpredicts that every segment deletion by dissociation can be compensated for by spreading the features of a nearby melody. This means that the skeletal theory does not distinguish between onset deletion and coda deletion since both would leave an empty slot. Also, a skeletal theory does not differentiate between the deletion of moraic codas and nonmoraic ones.

However, it is cross-linguistically observed that compensatory lengthening occurs only in the aftermath of coda deletion, in languages with W-b-P, or vowel deletion for that matter. Moraic Theory captures this generalization very well, in that it assumes that only the deletion of moraic elements triggers compensatory lengthening. In this capacity, compensatory lengthening becomes motivated by the conservation of mora count.

(46) Moraic conservation (Hayes, 1989:285)

Compensatory Lengthening processes conserve mora count.

Since Moraic Theory assumes that onsets do not add to the mora count of syllables, it becomes evident why CL does not take place upon the deletion of onset segments or any other nonmoraic element.

Under the conception of CL, the gemination characterizing forms such as darbattu can be interpreted along the same line, whereby geminating the consonant $/ t /$ can be argued to be triggered by the deletion of the vowel /a/ of the affix /at/. This seems to be consistent with 


\section{The Behavior and Representation of Geminate Consonants in Moroccan Arabic}

the thinking of Moraic Theory since a vowel is underlyingly associated with a mora. Thus, it could be argued that the deleted vowel leaves behind it a lingering mora. In order to preserve the mora count of the word, the onset of the ensuing syllable links to the empty mora, giving rise to a word-internal geminate structure. A schwa is then inserted to replace the deleted vowel as the nucleus of the syllable. The details of this process are illustrated by the representations in (47) below.

(47) Compensatory lengthening in MA under the moraic approach

a.

b:

c.

d.

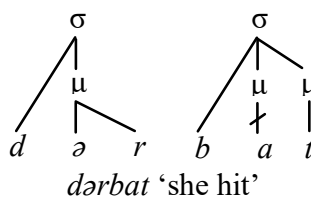

darbat 'she hit'
$\Lambda_{t}^{\sigma}$

darbat 'she hit'

\section{Deletion}

$\mu$ (lingering mora)

Resyllabification

Affixation and resyllabification

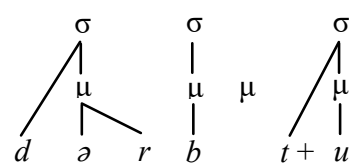

/dar.b.tu/ 'she hit+ him'

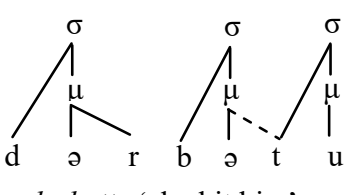

Compensatory lengthening and resyllabification

Unfortunately, MA does not contain other cases of deletion that could make the asymmetrical nature of CL clearer. What we have in mind is a case where the deletion of a nonmoraic element, say an onset, does not call for CL, while deleting moraic elements, like vowels and codas, does. Actually, it is very hard to establish this asymmetry in a single language. However, such an asymmetry is cross-linguistically adduced.

Next, we continue to show how the adopted moraic approach handles the geminates derived phonologically by assimilation as well as those derived morphologically by means of word derivation. Segments in moraic phonology are associated directly with moraic or syllabic nodes, in lieu of skeletal positions. With this in hand, we can think of assimilation as spreading some melodic material from one prosodic position to another. In our case of assimilation, spreading goes from the first radical segment associated directly to the syllable node, by virtue of being an onset, to the head mora left by the dissociated melody 
representing the definite article.

(48) Total assimilation in MA under the moraic approach
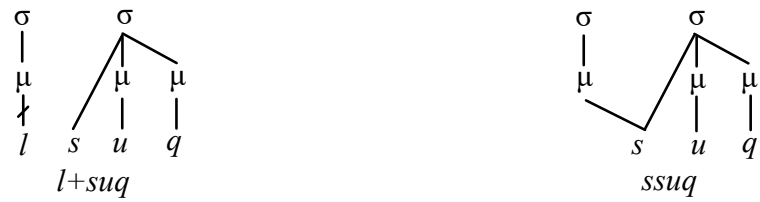

A moraic approach to geminates assumes that every geminate, be it lexical or derived, is moraic. To maintain this generalization, it is widely argued that a morphologically derived geminate emerges from the affixation of a mora. When it attaches to a singleton, the mora creates a geminate which is indistinguishable from other lexical or phonological geminates, except that it has a morphemic status as it adds meaning by creating new lexical items (or word forms like in the case of the imperfective form in Tashlhit (Bensoukas, 2001)).

Along the same lines, the geminates that characterize the derivation of causative verbs, agent nouns and instrument nouns are assumed to be the outcome of affixing a mora to help derive those forms. Here, we will illustrate by referring to the case of causative verbs. We account for the causative formation in terms of stem modification, by lengthening the second radical element, as mora affixation to a root, following Lombardi \& McCarthy (1991), Samek-Lodovici (1993), Bensoukas (2001) and Noamane (2014). The essence of this analysis can be extended to the cases of agentive and instrumental nouns as well. An example is given below:

(49) Morphological gemination in MA under the moraic approach

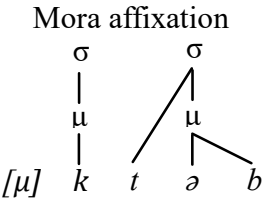

$[\mu]+k t a b$
Infixation and resyllabification

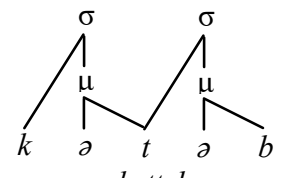

$k a t t a b$

The remaining issue now is to understand how the moraic approach plays into the integrity displayed by geminate consonants with regard to schwa epenthesis in MA. It appears that representing geminates as a one-root-node structure associated with a mora explains geminate-integrity straightforwardly since unit segments are inherently indivisible. In this way, the integrity of geminates is minimally captured, unlike in the skeletal approach which calls upon the non-crossing association lines constraint to explain such a property.

This indivisible monolithic nature of geminates in Moraic Theory turns out to be a problem for part of our data. Precisely, it is well attested that geminates in MA can be split by means of inserting some vocalic material between what appears, given this vocalic insertion, to be a geminate cluster. By way of illustration, let us reconsider the case of the 
The Behavior and Representation of Geminate Consonants in Moroccan Arabic

past participle mentioned earlier:

\begin{tabular}{|c|c|c|}
\hline Root & Verb & Past Participle \\
\hline$/ s d d /$ & Sadd & 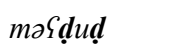 \\
\hline$/ \int q q /$ & $\int_{\partial} q q$ & $m \partial \int \boldsymbol{q} u \boldsymbol{q}$ \\
\hline$/ \int d d /$ & $\int \partial d d$ & $m a \int d u d$ \\
\hline$/ \hbar d d /$ & $\hbar \partial d d$ & $m ə \hbar d u d$ \\
\hline
\end{tabular}

There is no way the vowel $/ u /$ could break the relevant geminates if they were indivisible monolithic segments. The other closely related problem is that our data can pose to a monolithic conception of geminates has to do with the triggering of schwa epenthesis. As mentioned before, the context for schwa epenthesis should be at least a tri-consonantal sequence. Interestingly, roots that consist of a consonant plus a geminate (i.e., CG) qualify as an environment for schwa epenthesis, hence, contrary to the prediction made by the moraic representation, the relevant geminates count as two segments.

These two issues constitute very serious challenges that could work as strong arguments against the moraic approach of geminates, and thus jeopardize our goal to advance a moraic treatment of geminates in MA. Still, since the mora associated with the geminate is primarily a prosodic unit, these issues could be resolved at the segmental level without sacrificing the good contributions of the moraic approach. This can be done by representing geminates as two-root nodes linked to a mora, in lieu of the standard representation of a moraic one root node. In other words, the problem has to do with the strictly built-in monolithic nature of geminates and not their moraic status. By taking this step, it becomes possible to maintain a degree of structural parallel between geminates and clusters in accordance with the observed facts that our data reveals.

\subsubsection{The two-root node theory of length}

The two-root node theory of length was proposed by Selkirk (1990) as an alternative to both the skeletal approach and the moraic one. For Selkirk, geminates should be represented with two identical root nodes whose stricture and place features are shared. This representation is schematized below:

(51)

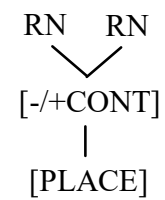

This model benefits from the development brought by the theory of feature geometry (Clements, 1985), whereby features are hierarchically organized. Under this conception, the root node functions as an anchor point for the other intermediate feature nodes. For a feature to be realized in the output form, it should be licensed by some root node. Since geminates can be represented with two root nodes, the relevant features get realized twice 
in the output.

The phonotactics of MA resonates well with the premise of the two-root node model, in the sense that other sequences of consonants with identical sonority levels are permitted. Particularly, sequences of stop-stop, fricative-fricative and nasal-nasal are easy to be found. Specific examples are given below:

(52) Identical sonority sequences in MA

a. Stop-stop: $d b ə \hbar$ 'to slaughter'; ktab 'to write'

b. Fricative-fricative: $\hbar s a b$ 'to cout'; ffal 'to fail'

c. Nasal-nasal: nmal 'ants'; mnəS 'to forbid'

However, the two-root node model fails to characterize the underlying moraic properties of geminate consonants attested across a wide range of languages. The question now is: can we think of a flexible model of representation that can account for the segmental and moraic patterning of geminates?

\subsection{The proposed model: A moraic two-root node model}

Though the motivation behind proposing a two-root node model was to replace the other models in the market, our goal is to sustain the moraic model and supplement it with the two-root node one. This can be easily done since the two models make predictions about different levels of representation. A moraic level is needed to capture the prosodic phenomena that involve geminates, while the root level is required to tackle the segmental issues. This is specifically necessary in the case of languages that distinguish between geminates and singletons in terms of weight and, at the same time, maintain a degree of patterning between geminates and consonant clusters.

(53) The moraic two-root node model

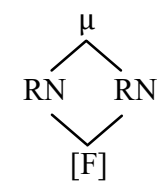

The idea of a hybrid model that combines both a prosodic level and a segmental one first came up in Hume et al. (1997) and was later developed in Muller (2001). The central premise underlying this model is that the weight specification of geminates is assigned on a language-specific basis rather than being inherent, whereas length is segmentally encoded via the multiple associations to two slots on the skeletal tier. This is represented in the following way:

$$
\underbrace{\mu}_{[\mathrm{RN}]} \mathrm{X}
$$




\section{The Behavior and Representation of Geminate Consonants in Moroccan Arabic}

In this sense, the Composite Model reaffirms the assumptions of the skeletal approach about the structural patterning between geminates and consonant clusters with the main exception of incorporating a moraic level for the sake of eschewing the prosodic problems that a skeletal level alone fails to account for. Therefore, in the presence of a moraic level, the timing slots are stripped off their prosodic nature to be merely segmentally relevant. Under this conception, geminates and singletons are put on an equal footing weight-wise, in that WBP applies (or does not apply) to them equally. In this way, a geminate can be assigned a mora only when it is in a coda position, which explains why the mora is restrictedly associated with the first member of the geminate sequence in the above representation.

This version of the hybrid model differs from ours in two ways. First, this model captures the segmental properties of geminates in terms of association with slots on the skeletal tier, whereas in our model the skeleton is dispensed with entirely. Instead, melodic elements are linked directly to prosodic nodes. In the presence of a moraic level, skeletal tiers become unnecessary and redundant. Thus, a hybrid model that replaces timing slots with root nodes is preferable (Stuart Davis, personal communication).

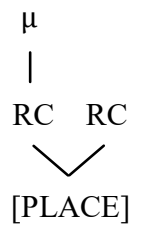

Second, the mora is not part of the underlying structure of geminates. Under the assumption that singletons and geminates are equally weightless, the latter get assigned weight on a language-specific basis. In our model, the mora is underlying. Hence, geminates are expected to be moraic wherever they occur. Also, in our model, the mora is linked to both root nodes at the same time. It cannot pick one root node over the other since the information about their syllabic positions is not available yet.

Injecting a two-root node level into our model requires a revision of some of the accounts we suggested earlier under an exclusively moraic model. This primarily concerns the cases of total assimilation, compensatory lengthening and morphological gemination. The geminates involved in these processes were thought to be derived as consisting of a single root node linked to a mora, resembling the structure of lexical geminates. In order to maintain a unified structure between all types of geminates (i.e., derived or underlying), we should find a way to derive the two-root structure in derived geminates as well.

To achieve a unified representation of geminates in MA, we suggest a structure motivated root node epenthesis process, whereby an empty root node is inserted to provide a segmental interpretation to the new weight of the spreading consonant. Then, the newly 
inserted root node shares the mora and the features of the spreading root node. In this way, the derived structure would exactly match the structure proposed for underlying geminates. This epenthesis process is needed to derive the right structure of geminates generated by assimilation, CL and morphological lengthening.

(56) Deriving the moraic two-root node representation

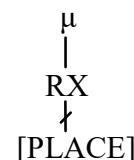

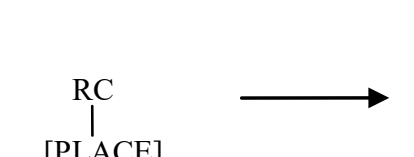

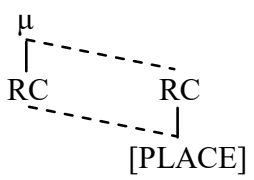

This solution is based on Selkirk's (1990) mora motivated epenthesis process devised to provide a two-root account of CL. However, the difference is that, for Selkirk, weight is not crucial to representing length. Rather, the latter is purely segmentally determined via the two-root node structure.

The central assumption embedded into claiming that a geminate underlyingly consists of a mora that is linked to two root nodes is that weight and length are in a corresponding relationship. That is, it is believed that both prosodic weight and segmental length are essential properties of making a geminate. Phrased differently, it is claimed that a consonant can be long only in the existence of both a moraic component and a segmental one.

As far as geminate integrity is concerned, we have previously seen that geminates in MA are prone to breaking by means of morphologically induced vowels (see the case of the past participle above). The question that arises from this fact is as follows: what form do geminates take when they get broken by vocalic material? Asked differently, how does vocalic breaking affect the phonological representation of geminates? In answering this question, we conjecture that when split up, the two root nodes constituting a geminate become independent of each other in two ways. First, each root node takes a copy of the feature set they have been sharing. Second, the mora dominating the root nodes gets erased after dissociating from both thanks to the stray erasure mechanism. This can be illustrated as follows:

(57) The fate of split geminates

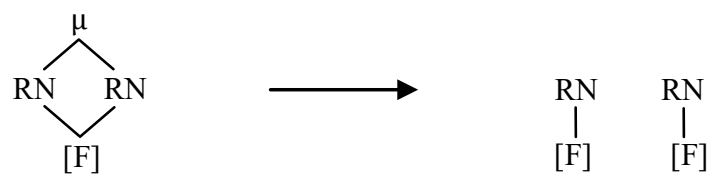

With regard to geminate syllabification, the moraic two-root node model combines the predictive powers of the Standard moraic model and the two-root node model. This means that geminates can be syllabified under moraic terms and segmental terms. In order to 


\section{The Behavior and Representation of Geminate Consonants in Moroccan Arabic}

control the overpredictive power of the moraic two-root node model, we assume that the syllabification algorithm has no access to the segmental level of geminates. Therefore, geminates should be syllabified under moraic terms only.

\section{Conclusion}

In this paper, we have tried to describe the phonological behavior of geminates in MA and, on that basis, advance a representational model that can best capture the observed tendencies without falling behind in terms of keeping up with theoretical development in phonological theory. First, we have shown that geminates in MA display a dual behavior by combining properties of both unit structures (i.e., singletons) and cluster structures (i.e., consonant sequences). On the one hand, it has been shown that geminates pattern with consonant clusters with regard to lexical distribution, schwa triggering, hetrosyllabicity, and breaking by means of full vowels. On the other hand, it has been noted that geminates maintain their integrity in relation to schwa epenthesis, behaving more like monolithic structures.

In response, we have attempted to identify the most appropriate representational framework that could naturally account for the inconsistency characterizing geminate behavior in MA. To this end, it has been shown that, in nonlinear phonology, a geminate could be represented as a single melodic element associated either to multiple skeletal positions, a mora or two root nodes. While the skeletal approach came very close to fully characterizing the patterning of geminates in MA, it has been criticized for failing to explain the cross-linguistic asymmetries related to weight sensitive phenomena, such as compensatory lengthening, stress placement and word size minimality. Alternatively, Moraic Theory has been successful in explaining the asymmetrical variations displayed by weight sensitive patterns, and was accordingly considered a better representational framework. However, a moraic approach to geminate representation fails miserably in accounting for the bi-positional properties of geminates in MA and a slew of other languages. As a reaction, a hybrid model was suggested whereby geminates are represented as underlyingly moraic and bi-positional by virtue of consisting of a mora shared by two root nodes. It was argued that this could provide a universal representation of geminates that can explain their varying patterning across languages.

$\begin{array}{ll}\text { Abbreviations and symbols } \\ ] & \text { Boundary } \\ \sigma & \text { Syllable } \\ \mu_{\mathrm{c}} & \text { Consonantal Mora } \\ \mathrm{C} & \text { Any Consonant } \\ \mathrm{CiCi} & \text { Identical Consonants }\end{array}$

Macrolinguistics (2021)

$\begin{array}{ll}\text { CL } & \text { Compensatory Lengthening } \\ \text { CONT } & \text { Continuant } \\ \text { F } & \text { Feature Bundle } \\ \text { G } & \text { Geminate } \\ \text { MA } & \text { Moroccan Arabic }\end{array}$


Ayoub Noamane

$\begin{array}{llll}\text { MC } & \text { Morphological Causative } & \text { RN } & \text { Root Node } \\ \mathrm{N} & \text { Node } & \mathrm{V} & \text { Any Vowel } \\ \text { OCP } & \text { Obligatory Contour Principle } & \text { V: } & \text { Long Vowel } \\ \mathrm{R} & \text { Root } & \text { X-slots } & \text { Any Skeletal Position } \\ \text { RED } & \text { Reduplication } & & \end{array}$

\section{References}

Bennis, S. \& E. Iazzi. 1995. Morphologie du Verbe Causatif en Arabe Marocain [J]. Langues et Littératures, 13:79-96.

Bensoukas, K. 2001. Stem Forms in the Nontemplatic Morphology of Berber [D]. PhD Dissertation. Rabat: Mohammed V University.

Bensoukas, K. \& A. Boudlal. 2012a. The Prosody of Moroccan Amazigh and Moroccan Arabic: Similarities in the phonology of Schwa [A]. In T. Borowsky, S. Kawahara, M. Sugahara \& T. Shinya (eds.). Prosody Matters: Essays in honor of Lisa Selkirk [C]. London: Equinox, 3-42.

Bensoukas, K. \& A. Boudlal. 2012b. An Amazigh Substratum in Moroccan Arabic: The prosody of Schwa [J]. Langues et Littératures, 22:179-221.

Blevins, J. 2005. The Typology of Geminate Inventories: Historical explanations for recurrent sound patterns [A]. In Seoul Linguistics Forum 2005 [C]. Seoul: Seoul National University, 121-137.

Chomsky, N. \& M. Halle. 1968. The Sound Pattern of English [M]. New York: Harper and Row.

Clements, G. N. 1985. The Geometry of Phonological Features [J]. Phonology, 2(1):225-252.

Curtis, E. 2003. Geminate Weight: Case studies and formal models [D]. PhD Dissertation. Washington: University of Washington.

Davis, S. 1994. Geminate Consonants in Moraic Phonology [A]. West Coast Conference on Formal Linguistics [C]. 13:32-45.

Davis, S. 1999. On the Moraic Representation of Underlying Geminates: Evidence from prosodic morphology [A]. In R. Kager \& H. van der Hulst (eds.). The Prosody-Morphology Interface [C]. Cambridge: Cambridge University Press, 39-61.

Davis, S. 2011. Geminates [A]. In M. van Oostendorp, C. J. Ewen, E. Hume \& K. Rice (eds.). The Blackwell Companion to Phonology 2 [C]. Malden \& Oxford: Wiley-Blackwell, 837-859.

Dmitrieva, O. 2017. Production of Geminate Consonants in Russian: Implication for typology [A]. In H. Kubozono (ed.). The Phonetics and Phonology of Geminate Consonants [C]. Oxford: Oxford University Press, 34-65.

Goldsmith, J. 1976. Autosegmental Phonology [D]. PhD Dissertation. Cambridge: The MIT Press.

Guerssel, M. 1977. Constraints on Phonological Rules [J]. Linguistic Analysis, 3(3):267-305.

Guerssel, M. 1978. A Condition on Assimilation Rules [J]. Linguistic Analysis, 4(3):225-253.

Hart, M. E. 1991. The Moraic Status of Initial Geminates in Trukese [A]. In L. A. Sutton, C. Johnson \& R. Shields (eds.). Proceedings of the 17th Annual Meeting of the Berkeley Linguistics Society [C]. 107-120.

Hayes, B. 1986. Inalterability in CV Phonology [J]. Language, 62(2):321-351.

Hayes, B. 1989. Compensatory Lengthening in Moraic Phonology [J]. Linguistic Inquiry, 20(2):253-306.

Hayes, B. 1995. Metrical Stress Theory: Principles and case studies [M]. Chicago: University of Chicago Press.

Hume, E., J. Muller \& van A. Engelenhoven. 1998. Non-moraic Geminates in Leti [J]. Phonology, 14(3): 371-402.

Hyman, L. 1985. A Theory of Phonological Weight [M]. Dordrecht: Foris Publications.

Kenstowicz, M. \& C. Pyle. 1973. On the Phonological Integrity of Geminate Clusters [A]. In M. Kenstowicz \& C. Kisseberth (eds.). Issues in Linguistic Theory [C]. Hague: Mouton Publishers, 27-43.

Kiparsky, P. 2008. Fenno-Swedish Quantity: Contrast in stratal OT [A]. In B. Vaux \& A. Nevins (eds.). Rules, Constraints, and Phonological Phenomena [C]. Oxford: Oxford University Press, 185219.

Kubozono, H., J. Ito \& A. Mester. 2008. Consonant Gemination in Japanese Loanword Phonology [A]. In 


\section{The Behavior and Representation of Geminate Consonants in Moroccan Arabic}

18th International Congress of Linguistics, Seoul [C]. 953-973.

Kubozono, H. (ed.). 2017. The Phonetics and Phonology of Geminate Consonants [M]. Oxford: Oxford University Press.

Leben, W. R. 1973. Suprasegmental Phonology [D]. PhD Dissertation. Cambridge: Massachusetts Institute of Technology.

Leben, W. R. 1980. A Metrical Analysis of Length [J]. Linguistic Inquiry, 11(3):497-509.

Levin, J. 1985. A Metrical Theory of Syllabicity [D]. PhD Dissertation. Cambridge: Massachusetts Institute of Technology.

Lombardi, L. \& J. McCarthy. 1991. Prosodic Circumscription in Choctaw Morphology [J]. Phonology, 8:37-71.

McCarthy, J. 1979. Formal Problems in Semitic Phonology and Morphology [D]. PhD Dissertation. Cambridge: Massachusetts Institute of Technology.

McCarthy, J. 1981. A Prosodic Theory of Nonconcatenative Morphology [J]. Linguistic Inquiry, 12:373-418.

McCarthy, J. J. 1986. OCP Effects: Gemination and antigemination [J]. Linguistic inquiry, 17(2):207-263.

McCarthy, J. J. \& A. Prince. 1986. Prosodic Morphology [Z]. Ms. Amherst: University of Massachusetts, Waltham: Brandeis University.

Muller, J. S. 2001. The Phonology and Phonetics of Word-initial Geminates [D]. PhD Dissertation. Columbus: The Ohio State University.

Noamane, A. 2014. Aspects of the Morpho-phonology of Causative Verbs in Moroccan Arabic: An optimality-theoretic approach [M]. Sarrbrucken: Lambert Academic Publishing.

Noamane, A. 2018a. On the Integrity of Geminates in Moroccan Arabic: An optimality theoretic account [J]. Journal of Applied Language and Culture Studies, 1:133-164.

Noamane, A. 2018b. Patterns of Gemination in Moroccan Arabic: Issues in phonology and morphology [D]. PhD Dissertation. Rabat: Mohammed V University.

Noamane, A. 2018c. A Root-and-prosody Approach to Templatic Morphology and Morphological Gemination in Moroccan Arabic [J]. International Journal of Arabic Linguistics, 4(2):331-369.

Noamane, A. 2020a. Consonant Gemination in Moroccan Arabic: A constraint-based analysis [J]. Journal of Applied Language and Culture Studies, 3:37-68.

Noamane, A. 2020b. A Non-templatic Approach to the Formation of the Past participle in Moroccan Arabic [J]. SKASE Journal of Theoretical Linguistics, 17(5):42-65.

Saib, J. 1977. The Treatment of Geminates: Evidence from Berber [J]. Studies in African Linguistics, 8(3):299-316.

Samek-Lodovici, V. 1993. A Unified Analysis of Crosslinguistic Morphological Gemination [A]. In P. Ackema \& M. Schoorlemmer (eds.). Proceedings of CONSOLE I [C]. The Hague: Holland Academic Graphics, 265-283.

Schein, B. \& D. Steriade. 1986. On Geminates [J]. Linguistic Inquiry, 17(4):691-744.

Selkirk, E. 1990. A Two-Root Theory of Length [A]. University of Massachusetts Occasional Papers [C]. Amherst: GLSA publications, 14:123-171.

Tyler, S. A. 1969. Koya: An outline grammar: Gommu Dialect [M]. Berkeley: University of California Press.

Watson, J. C. E. 2002. The Phonology and Morphology of Arabic [M]. New York: Oxford University Press. 